\title{
Subversion of the Masculine Gender Roles in the Malayalam Film,
} "Kumbalangi Nights"

\author{
Dr. Thara Gangadharan \\ Assistant Professor \\ Department of English \\ Bharata Mata College \\ Thrikkakara, Kochi, Kerala, India \\ thara@bharatamatacollege.in
}

Abstract

Like most of the regional films in India, Malayalam film industry has undergone radical changes which is ultimately a reflection of the societal changes in Kerala. The 2019 film in the regional language, Malayalam, Kumbalangi Nights, directed by Madhu C Narayan enters the list of such films. The film became a point of discussion in the Malayalam film industry as it won the Kerala State film award in 2020. The film has taken a diverse look at the societal problems of the lower middle-class people in the city of Kochi. The study is an analysis of the way in which the film has subverted the popular notions of masculinity and redefined the patriarchal world views within the family structure.

Keywords: Masculine, Feminine, Patriarchy, Gender Roles.

Every regional film in India is considered as metanarratives of the way in which the Indian society at large is portrayed in a miniature format. A radical change in the portrayal of characters and the ways in which stories are represented in Indian regional films are visible nearly ten years after the millennium. This radical shift is visible in Malayalam films after 2012 which marked the change to a so-called new generation cinema. As a popular visual 
medium which is influencing the society these times, cinema became a medium for communicating the essential social changes that the intellectuals in the society are expecting. The film, Kumbalangi Nights can be regarded as a typical new generation film in Malayalam which has subverted so many preconceived notions of power structures in the society. The paper is an attempt to analyse the film in a critical manner in which there are instances in the film which subverts the popular notions of masculinity in Kerala society. Though the film was set in the outskirts of the Kochi city, how the lower middle-class people is struggling to lead their lives in a way which collides with the development of the area as a metropolitan city is well portrayed in the story.

Kumbalangi Nights is a 2019 film directed by Madhu C Nayarayan and screen play from Shyam Pushkaran. It is a story of four brothers, Saji, Boney, Bobby and Frankie. The story parallels with the story of Shemmy who came to the story as a newly-wed man to Soumya and is living with her mother (a widow) and the younger sister Baby. When the story opens up, the elder brothers Saji and Bobby are shown as aimless, lazy and quarrelsome. Saji, with a migrant worker Vijay has taken up some ironing business. After a severe quarrel with Bobby, Saji attempted suicide and when his attempt to save Saji, Vijay lost his life. The story moves through the life of these four brothers and how their lives were under turmoil after they lost their father and their mother abandoned them to choose God's way. The youngest one Frankie, a school going one with talents in sports, is frustrated by the ways of these brothers, though he is attached closely to the dumb, Boney. Mike McCahill speaks about the mastery of the director Mahesh Narayanan in the film,

Narayanan's direction assumes a forgiving quality: it's never indulgent, however becalmed matters seem, but it insists on allowing the brothers time and space, in the hope they'll see the error of their ways and take some form of responsibility before the credits roll. (Mike) 
The situation in Saji's home and the lack of bondage between the boys are evident in the initial scenes of the movie. But after Vijay's death Saji needs to took over the family along with Vijay's wife and the new-born baby. Here the definitions of the masculine, heroic ideologies of the protagonist along with others in the movie come to a shift in the depiction. Saji took over the role of a 'housewife' in the home. The scene in which he cries his hearts out in front of the psychiatrist itself is a subversion of the definition of a fearless and brave hero in traditional films. Emotional turmoil for men in movies used to be flooded with their reaction as anger or frustration and a hero like Saji is shown as crying 'like women'. After Saji took over the duties of the kitchen he began to show the tolerance usually associated with women to his quarrelsome siblings. The stereo typical gender roles related with the social constructions of reality faces a challenge in the portrayal of the protagonist Saji in the film. Both the masculine and feminine gender roles in society are framed by the ways in which both the roles are performed repeatedly.

"Roles are defined by expectation and norms, sex roles by expectations attaching to biological status." (Connell 25). Various sociologists have argued that the masculine gender roles that a person follows is a result of the socio-cultural factors that affect the person.

Gender-role socialization refers to the processes through which individuals acquire attributes appropriate to males and females. Examination of gender roles indicates differences in the content of roles seen as appropriate for men and women. Men are socialized more often than women to be active and to ignore their feelings of weakness. Men are expected to be more independent, autonomous, and strong. It is more acceptable for women to express a wide range of emotions, to pay attention to their moods, and to seek out others for help. While men may be encouraged to be independent, women are taught to be more interdependent. The term interdependence 
refers to the ability to express interpersonal needs, particularly in emotional relationships, and to relate meaningfully to others in relationships (Greenglass 1982).

A critique of such gender roles can be seen in the writing of feminist writers like Judith Butler through Gender Trouble.

The ways in which the masculine gender acts in society and the jobs that they choose outside the family structure which keeps the female completely embedded in the responsibilities of home and child care. This traditional notion of masculine sex-gender roles are seen in popular cinema too, though there are changes in the women centred films at times. When considering the characters of Saji and Bobby, the traditional notions of these gender roles face a radical change. Saji took over the household duties and making use of his hereditary skill of fishing for a living. This role change of the protagonist to a responsible man who sheds his ego in having the dominant role of a 'man' in society which is evident from his behaviours to others in the first half of the story.

When moving to the behaviours of the counterpart of Saji, Shemmy, it is evident that Shemmy is a representative of the majority of men in Kerala society, who need everything perfect. This is evident in the scene in which Shemmy looks at the mirror and tells the advertisement caption of the shirt brand, Raymond, "Raymond, the complete man". He is also the normal public who sees the white, slim and handsome man as the 'perfect' one in the society. When he talks with Saji he says, he is from a 'neat, middle class family and he has a neat profession unlike the below average living conditions of Saji's family'.

The ways in which Shemmy intrudes into the dominant patriarchal position of Soumya's family and he seeks the power and authority to control even the mother makes the thread of the story. The urge of Shemmy to attain power is evident in the scene in which he tells everyone to sit together for dinner and moves his chair to the chief position of the dining table. This scene indicates the inner joy that he experiences for becoming the centre of the 
house as well as the power head to the rest of the family members. Within months he attains the power to control Smitha's sister Baby in her love affair with Bobby. He is able to be the centre of the family at the same time becoming trust worthy and loving towards his mother-in -law and wife. Only Baby is the one who understands the urge for power in Shemmy. Shemmy's controlling behaviour becomes in peak in the climax of the movie. When Soumya and Baby began to talk back, Shemmy physically attacks them cruelly and Bobby and his brothers rescue them by attacking back Shemmy and trapped him in a big fishing net.

The film Kumbalangi Nights redefines the sex before marriage which is considered as a taboo and a matter of honour in Kerala. Boney, the second brother of Saji, keeps the relationship with a foreign woman and they indulge in sex in Baby's home-stay. The way in which Shemmy reacts to it, is that of a male-chauvinist. He doesn't allow them stay for a minute long soon after he found out it through the window shades. Saji's home becomes an open space which welcomes them too in the middle of so many hurdles that they already had. Here the audience could see the broad mind set of the youngsters in the house which were thought to be worthless and disintegrated. When they began to need the presence of their mother with them for the marriage of Babby and Bobby, they went to call back her from the monastery she lives, but she denies it. Later on, Saji empathises with her, though she was his step mother. Saji told that she had seen her struggling throughout her young age for these kids. Such an empathetic mention from Saji can be analysed as the worth of the real masculinity in Saji.

Regarding the gender roles of women and men in social setting, Simon De Bouvier famously stated that women are not born so but become women through socialization, the gender roles ascribed to a particular gender, whether masculine or feminine is the result of such socialization. This is evident in the way in which Shemmy's psyche teaches him that power equals masculinity. Hence, he controls the family through power at the same time Saji 
could handle the whole scattered family through his natural self as the bread winner and a genuine brother to them all. Nancy Chodrow, a famous sociologist examines the ways in which the mother-child relationship changes the gender roles of a person in society. Accordingly, Chodrow argues that attachment with the mother is broken at some point of time in order to achieve a separate sense of self. When the girl child imitates her mother, the boy child will be moving away from his mother for reviving his natural self as a masculine one. Here in the story when Saji understood the difficulty of their mother to come back to them, it is really evident that he finds out the hurt that she had when she looked after the orphaned children in a naïve material condition of the home.

The great joke of the film is how it completely subverts our expectations of a "revenge movie" and, in the process, strikes a blow at the heart of the herocentric masala movie. Mahesh is the gentlest of men, and yet, owing to the culture of masculinity in patriarchal societies, it doesn't take much to incite primal passions that leave even someone like him baying for blood. In a typical masala movie with such a setup, the second half would simmer with the prospect of the showdown between good and evil. But here, the "villain" simply vanishes. The hero is left nursing his wounded pride and the realisation that life goes on. The revenge promised in the title is almost an afterthought. (Baradwaj)

From the perspective of the women characters in the movie, it is evident that there are changes in the gender expectations of women in popular cinema in Malayalam. The typical hero image is not applicable to Bobby when Babby admits to her sister telling that Bobby is not a good guy and also a dump fool, though she loves him. Baby knows well the material condition of the brothers and the ethics and morals that they are reluctant to follow in their lives. Though Bobby wants the foreign girl to go out of the home, Boney is reluctant to accept the popular beliefs that the society always have suspicious feeling towards such 
relationships. It is a brave decision that Boney and Saji leads a life of their own. There the audience could see such decisions from Saji accepting the wife of Vijay and their child, Bobby took initiative to go for fishing again and so on. Such serious decision that they are taking against the popular concepts and ethics-moral codes of the society makes the story a unique one in depiction.

It is worth mentioning that the film Kumbalangi Nights keeps away all the sophisticated outlooks of the main actors in the story. All those who act in the film shows their original selves and the story highlights the ways in which they could portray their lives as it is. In the middle of worthlessness that they feel in the initial scenes of the story, the development of those characters is really evident to the audiences too. The audience may feel that they are also growing along with the characters. The gender roles that popular film industry has defined over decades have shaken by the characters of Saji, Boney, Bobby and Shemmy. We could see more masculine traits in Babby and a little bit more of a feminine in Saji. All the characters, especially the male characters, can be analysed as a subversion of the gender roles usually ascribed to them in popular cinema. 


\section{References}

"Kumbalangi Nights Review $\{3.5 / 5\}$ : A Film That Is Well-Worth a Watch." The Times of $\begin{array}{llllll}\text { India, } & \text { The } & \text { Times }\end{array}$ timesofindia.indiatimes.com/entertainment/malayalam/movie-reviews/kumbalanginights/movie-review/67881410.cms. Accessed on 15 October 2020.

Benjamin, Jessica. “A Desire of One's Own: Psychoanalytic Feminism and intersubjective Space”. Feminist Studies/Cultural Studies: Language, Discourse, Society. London: Palgrave Macmillan, 1986.

Chodrow, Nancy. The Reproduction of Mothering: Psychoanalysis and the Sociology of Gender. University of California Press,1992.

Connel, $R$ W. Masculinities. $2^{\text {nd }}$ edn. Polity Press: Cambridge, 2005.

Gokul Singh, K Moti and Wimal Dissanayake. Indian Popular Cinema; a Narrative of Cultural Change. Orient Longman: Hyderabad, 1998.

Greenglass, E.R. "Gender Role Stress and Health." International Encyclopedia of the Social \& $\begin{array}{llll}\text { Behavioral Sciences, } & \text { Pergamon, } & 2 & \text { Nov. }\end{array}$ www.sciencedirect.com/science/article/pii/B0080430767038626. Accessed on 10 October 2020.

Jain, Jasbir. Indigenous Roots of Feminism; Culture, Subjectivity and Agency. Sage: New Delhi, 2011.

McCahill, Mike. "My Streaming Gem: Why You Should Watch Kumbalangi Nights." The Guardian, Guardian News and Media, 1 June 2020, www.theguardian.com/film/2020/jun/01/my-streaming-gem-watch-kumbalanginights.

Rangan, Baradwaj, et al. "Southern Lights: Men, Maleness, Masculinity And Family In Kumbalangi Nights." Film Companion, 15 May 2020, 
www.filmcompanion.in/opinion/malayalam-opinion/southern-lights-men-malenessmasculinity-and-family-in-kumbalangi-nights/. Accessed on 12 October 2020.

Robinson, Sally. "Deconstructive Discourse and Sexual Politics: The "Feminine" and/in Masculine Self-Representation". Cultural Critique: The Construction of Gender and Modes of Social Division. University of Minnesota Press: Minnesota, 1989.

Winarick, Kenneth. "Thoughts on Greed and Envy". The American Journal of Psychoanalysis, 70, (317-327). 2010. www.palgrave-journals.com/ajp/. Accessed on 20-01-2020. 